\title{
ROBERTO SCHWARZ: UM CRÍTICO DIALÉTICO NA PERIFERIA DO CAPITALISMO
}

Maria Elisa Cevasco*

Qual o diferencial da crítica dialética? Pelo menos em sua manifestação mais conhecida em nossos dias, a da prática da escola de Frankfurt a partir dos anos 1930, ela se destaca por sua capacidade de estilhaçar a linha que tradicionalmente separa a esfera da cultura da esfera da sociedade que a produz, ou, para falar a linguagem mais antiga, as obras do espírito dos afazeres da produção e reprodução da vida, ou ainda se quisermos falar como o marxismo ortodoxo, a linha que separaria a base da superestrutura.

Sabemos que pelo menos desde o Romantismo, a tarefa principal da crítica cultural hegemônica foi a de erigir um domínio separado para a cultura, um domínio de bens espirituais a partir do qual se poderia criticar o mundo material da produção do valor. Esse movimento levou a uma visão idealizada de cultura como a herança da humanidade, que seria passada de geração a geração, conservando os significados que definiriam o humano.

\section{*maece@usp.br}

Professora Doutora da Universidade de São Paulo.

Por seu lado, a crítica marxista vem insistir na ligação entre cultura e mundo social e marcar que a base - onde se dá a produção material - determina a superestrutura, a instância que a cultura divide com a religião, o sistema jurídico e filosófico. Como se sabe, no "Prefácio à Contribuição à Crítica da Economia Política”, Marx dá o sentido do processo ao dizer que "A totalidade dessas relações de produção constitui a estrutura econômica da sociedade, a base real onde se erige a superestrutura legal e política a que correspondem formas definidas de vida social e intelectual. O modo de produção da vida material condiciona o processo geral da vida social, política e intelectual. Não é a consciência dos homens que determina sua existência, mas sua existência social que determina sua consciência”. Nessa formulação, os dois polos da ação da crítica, produção espiritual e a material, a cultura e a sociedade, estão imbricados e podemos dizer, atropelando muitas diferenças, que o problema central da crítica dialética 
de inspiração marxista vai ser exatamente o de destrinchar as determinações recíprocas da arte e da sociedade. Dizendo a mesma coisa de outro modo, esta crítica vai investigar e esclarecer como a cultura produz e reproduz os significados e valores de uma determinada sociedade.

Deste ângulo, seu propósito vai ser, para adaptar uma formulação do primeiro grande crítico dessa tradição no Brasil Antonio Candido, o de descobrir e interpretar a realidade sócio-histórica concretizada nos produtos culturais. Desse ponto de vista, a arte não é um ornamento de um espírito imortal, mas a historiografia inconsciente de um tempo, para falar como Adorno, um dos expoentes da escola de Frankfurt.

A obra de Roberto Schwarz se insere nessa tradição, que está presente não só como elemento central de sua formação como crítico mas, também, no fato de que seu trabalho va dar continuidade e especificidade à trajetória da crítica dialética contemporânea.

No prefácio a um de seus livros mais importantes, Um mestre na periferia do capitalismo: Machado de Assis, ele dá as coordenadas que balizam sua obra: "Devo uma nota especial a Antonio Candido de cujos livros e pontos de vista me impregnei muito, o que as notas de pé-de-página não tem como refletir. Meu trabalho seria impensável igualmente sem a tradição - contraditória - de Lukács, Benjamin, Brecht e Adorno, e sem a inspiração de Marx".'

Certamente que seria fútil tentar medir a influência de Candido no projeto intelectual de Roberto Schwarz. ${ }^{2}$ Basta aqui lembrar três aspectos. $O$ primeiro é o da localização geográfica do pensamento. Candido, em diversas ocasiões, chama a atenção para o fato de que para um autor preocupado em estabelecer as ligações entre produção artística e sociedade, a localização em um país periférico acaba direcionando todo um programa crítico. Para Candido, isso já estava evidente na própria escola em que tanto ele quanto Roberto Schwarz se formaram, a hoje denominada Faculdade de Filosofia Letras e Ciências Humanas da Universidade de São Paulo. Fruto do desejo da burguesia paulistana de prover a cidade, que ia se tornando grande nos anos 1930, e mais um dos atributos da civilização, a faculdade acabou, também pelo fato de se interessar por assuntos locais, em criar uma tradição de "radicalismo modesto" que iria marcar sua história futura. Como relembra Candido,

Entre os professores e alunos de nossa faculdade há um pouco de tudo, é claro, mas estou pensando na sua tonalidade ideológica média enquanto instituição, que favorece o espírito de crítica e exame num sentido progressista, tornando mais difícil do que em outras escolas as manifestações coletivas de
1. SCHWARZ. Um mestre na periferia do capitalismo:

2. Ver a respeito da obra dos dois, o excelente livro de ARANTES. Sentimento da dialética na experiência intelectual brasileira. 
3. CANDIDO. "Feitos da burguesia", p.96

4. HADDAD (org). Desorganizando o consenso: nove entrevistas com intelectuais à esquerda, p.20. cunho reacionário e mesmo conservador. Um exemplo: em 1964, apesar da maioria de seus titulares serem provavelmente simpáticos ao movimento armado, ela foi a única Faculdade de São Paulo, salvo erro, que não fez manifesto de apoio. ${ }^{3}$

Some-se a esse radicalismo as injunções que a situação socio-histórica impõe ao pensamento não alienado em países onde a desigualdade social, para falar como Paulo Arantes, "rouba nosso fôlego especulativo." Em uma entrevista de 1994, citando Antonio Candido, figura central, como sabemos, para a formação da crítica cultural que esta universidade ajudou a por em circulação, Roberto Schwarz lembra como essa situação concreta determina nosso modo específico de pensar:

...o intelectual latino americano vive um engajamento peculiar, diferente do europeu. Ele está sempre contribuindo para a construção da cultura nacional, ainda incompleta. O país novo ainda em formação, é um pano de fundo especial, com regras próprias. Assim estamos sempre explicando o Brasil, salvando o Brasil, procurando uma brecha para que "ele" saia do atraso.

Além do engajamento, essa localização tem efeitos nas categorias que embasam o modo como se pensa. Como todos os outros países periféricos, o nosso tem que pensar a realidade usando categorias que tiveram origem em outros contextos sociais. Cabe ao pensamento responsável testar essas categorias frente às especificidades da nossa realidade. O próprio Roberto Schwarz mostra como essa consciência da contradição entre categorias externas e fenômenos internos acrescenta relevância e originalidade ao pensamento de Candido ${ }^{5}$. Sabemos que a obra seminal de Antonio Candido, os dois volumes de Formação da Literatura Brasileira: Momentos Decisivos, narra a história do desejo dos brasileiros de terem, como os demais países que lhe serviam de modelo, uma literatura. A questão central do livro é mostrar como se constitui um sistema literário em uma sociedade pós-colonial. Para isso, Candido enfoca os momentos decisivos dessa formação feita de importações de modelos do exterior. Demonstra como as condições sociais peculiares do Brasil acabam por modificar os gêneros e movimentos literários tomados emprestados de fora. $\mathrm{O}$ funcionamento desigual desses gêneros em circunstâncias distintas indica que estes não eram tão universais como se propunham. Aí uma inversão do espelho: não só aprendemos com os modelos estrangeiros, mas temos o que dizer a respeito de seu funcionamento real. O livro termina quando o processo de formação está completo, e o sistema está pronto para produzir seu primeiro romancista de envergadura mundial, Machado de Assis. Não por acaso, Roberto Schwarz vai dedicar grande parte de sua obra ao estudo de Machado e, marca também de sua relevância para o pensamento dialético contemporâneo, à invenção de categorias para pensar a especificidade do funcionamento
5. Ver, em especial, os ensaios sobre Candido coligidos em SCHWARZ. Sequências Brasileiras.

EM TESE

BELO HORIZONTE

v. 21

N. 1

JAN.-ABR. 2015

CEVASCO. Roberto Schwarz: Um crítico dialético na periferia do capitalismo

P. $11-23$ 
cultural na periferia e o que esta especificidade nos tem a dizer sobre o pensamento hegemônico que vem de fora.

No âmbito dos estudos literários Roberto Schwarz vai levar adiante um achado de Candido que é fundamental para os estudos da crítica cultural dialética. Em "Pressupostos, salvo engano, da Dialética da Malandragem”, ele mostra a originalidade de Candido em chegar a uma concepção de forma artística que lhe permite escrutinizar as ligações recíprocas entre a produção cultural e a sociedade, de modo a elucidar a obra e alcançar um conhecimento sui-generis sobre o que a sociedade que a produz oculta. Trata-se da noção de forma objetiva, a que Candido chegou sem conhecimento, na época, da noção correlata na obra de Adorno, que começou a circular nos meios acadêmicos mais adiante. Que diferença essa noção traz para os estudos literários?

Sabe-se que a concepção de forma artística na crítica tradicional é que o mundo é informe e cabe ao artista criar uma forma para dizer este mundo, criação essa que é seu toque de gênio. Para a crítica dialética, o mundo real é ele mesmo formado e cabe ao artista reelaborar essa forma. O que se ganha com isso? Por muito tempo, a crítica pensava a forma e o conteúdo de uma obra como dissociados: a forma seria o "privilégio da arte, aquilo que não existe no campo extra-artístico" e que, portanto, era autônoma, "uma estrutura sem referência" ${ }^{\circ}$. Ora, a questão para a crítica dialética é, como vimos, justamente juntar o que essa tradição separa: nas palavras de Candido, o central é mostrar como o externo se torna elemento da estrutura das obras, e, portanto, interno. Cabe à crítica examinar a organização formal das obras e verificar o que são capazes de revelar do complexo das relações histórico-sociais que estão aí plasmadas. Não se trata, como na crítica marxista mais tradicional, de ver na obra um reflexo da realidade que confirma o que já sabíamos antes sobre um determinado momento histórico. O contexto social não é visto aí como pano de fundo, mas como elemento constitutivo da obra, que nos permite enxergar esse contexto de forma nova e única. É nesse sentido que a arte, para a tradição dialética, tem um grande potencial cognitivo: através da análise de suas estruturas formais podemos ter um conhecimento específico de elementos da realidade social que não conhecíamos antes.

Um exemplo disso é a análise que Roberto Schwarz, na trilha de Adorno e de Candido, faz de Machado de Assis. Para muitos, Machado era o grande clássico brasileiro, que elevava a nossa literatura à de fora, um Laurence Sterne ou um Xavier de Maistre nos trópicos. Alguns críticos se referem aos narradores de seus romances tardios, narradores de quem a narrativa nos leva a duvidar de sua confiabilidade, como uma das marcas de seu modo de narrar. Para ficar em um só de seus romances, o Memórias Póstumas de Brás
6. SCHWARZ. "Adequação Naciona e Originalidade Crítica", p.31.
EM TESE

BELO HORIZONTE

v. 21

N. 1

JAN.-ABR. 2015

CEVASCO. Roberto Schwarz: Um crítico dialético na periferia do capitalismo

P. 11-23 
Cubas, um defunto autor escreve a seu bel prazer, deixando capítulos inconclusos ou se propondo a narrar um fato de sua vida para logo em seguida mudar de ideia. Onde muitos poderiam ver caprichos de um senhor culto e bem posto na vida, Roberto Schwarz vê, nessa escolha de modo de narrar, um feito de Machado de Assis. Este encontrou a forma para demonstrar a latitude de classe que têm os de cima em países periféricos. Brás se mostra ao leitor como um cidadão do mundo, cita com familiaridade grandes figuras do pensamento ocidental e usa os ditos avanços da civilização para justificar uma ordem social bárbara: basta lembrar um só dos muitos episódios, o que o nosso narrador monta como se fosse um cavalo seu escravo Prudêncio e justifica seus atos dizendo que este, provavelmente também gostava de brincadeira. Na leitura de Schwarz, vemos que a volubilidade do narrador - característica formal da obra - é de fato um conteúdo social, na medida em que está ancorada nos enormes privilégios concedidos aos de cima na situação social de um país como o Brasil do final do século XIX - mas será que não é assim até hoje?

Schwarz nos lembra que nem mesmo a ideologia do liberalismo, a mais prestigiosa da época, pode ser considerada válida nas condições reais do país. Afinal, esta ideologia pregava a igualdade formal entre os homens. Claro que tal ideologia, apesar de prestigiosa, não descrevia a realidade nos países centrais onde atuava para esconder, entre outras coisas, a exploração do trabalho de muitos para o benefício de poucos. Mas aqui essa ideologia não descreve nem mesmo a aparência da realidade, uma vez que imperava o escravismo, que não sustenta, é óbvio, nenhuma ideia de igualdade. Que tem isso a ver com a voz narrativa e com os desmandos de Brás?

O que ancora sua inesgotável volubilidade? Quem ou o que lhe autoriza falar com este senso de superioridade? A forma de narrar nos revela o fundamento social do privilégio que sustenta a maneira de falar de Brás. Tudo é permitido a um grão senhor no país da desigualdade. Mas, se lembrarmos que também nos países ditos civilizados reina o privilégio e não a igualdade, vemos que o romance de Machado tem poder de revelar também a ordem social dos países centrais onde esta ideologia liberal é formada. De fato, Brás ilustra a forma de subjetividade que se estrutura em uma sociedade que visa o lucro acima de tudo e que, por isso, está baseada em um individualismo predatório. Nesse sentido, mais do que uma idiossincrasia característica apenas da periferia do sistema, a subjetividade de Brás pode ser vista como a subjetividade característica da formação social burguesa, que vem dos países centrais e se amolda, com maior latitude, na periferia.

Dessa forma, a crítica de Roberto Schwarz expande a prática da dialética para incluir o trabalho de entender as 
7. SCHWARZ. "Sobre Adorno", p.47. especificidades da periferia e o quanto estas podem ajudar a esclarecer o centro. Vimos que ele coloca como centrais para sua formação a tradição de Luckás, Adorno, Benjamin e Brecht, e todos, assim como o nosso Autor, trabalhando sob a inspiração de Marx. Em diferentes entrevistas, Schwarz nos conta como se foi familiarizando com estes grandes nomes do que se conhece como Marxismo Ocidental. Encontrou a obra de Adorno quase por acaso, em uma livraria alemã de São Paulo. Segundo ele, a princípio se impregnou mais do clima argumentativo e dos tópicos do que propriamente de sua substância, uma vez que, para o jovem estudante de então, o livro era difícil demais, "por conta da densidade e da intensidade da exposição". ${ }^{7}$ Essa impregnação deixa marcas na prática de nosso crítico, e ler sua descrição dos feitos de Adorno nos lembra muito uma descrição dessa prática:

[Adorno] procura saber do que as formas falam, reagindo a elas como expressões da sociedade contemporânea no que ela tem de mais problemático e crucial. É claro que esta faculdade receptiva muito desenvolvida - ler Adorno não deixa de ser uma experiência humilhante pelo muito que ele vê onde o leitor não viu nada ou quase nada - é apenas a metade de sua força. A outra metade está na está no cuidado e na acuidade analítica com que ele esquadrinha a consistência e a inconsistência formal das obras, que ele interpreta... como a historio- grafia inconsciente de nosso tempo. Nada como comparar às produções rivais, inimigas da reflexão estético-social, a minúcia e a seriedade de suas análises. É ler e ver onde está o reducionismo, a desambição intelectual e o desapreço pela arte. ${ }^{8}$

Ele também nos conta que leu Lukács no seu curso de graduação em Ciências Sociais na USP, em especial no interior de um grupo de estudos que reunia jovens professores e alunos para ler O Capital e a tradição de crítica marxista. Lembra que o História e Consciência de Classe foi fundamental para impulsionar, no começo dos anos 1960, um espírito subversivo em relação ao capitalismo e de oposição ao comunismo oficial. Entre os membros do "Seminário de Marx", como ficou conhecido o grupo, criou-se uma corrente marxista independente. Muitas das obras desse grupo, que incluía Fernando Novaes, Fernando Henrique e Ruth Cardoso, José Arthur Gianotti, Otavio Ianni, Michel Lowy, Paul Singer, foram marcadas pela "inspiração lukacsiana."

Um dos achados originais desse grupo foi o de desmontar a forma "dualista" de se pensar o Brasil e chegar a uma nova concepção, mais propriamente dialética, de como se estrutura o país em relação aos países centrais. Essa nova intuição, desmonta as versões, vigentes tanto à direita quanto nos partidos comunistas, de que o país estava uma etapa atrasado em relação aos países do centro e que era necessário um esforço de arrocho ou de modernização, dependendo do
8. SCHWARZ. Martinha versus Lucrécia e outros ensaios, p. 46
EM TESE
BELO HORIZONTE
v. 21
N. 1
JAN.-ABR. 2015
CEVASCO. Roberto Schwarz: Um crítico dialético na periferia do capitalismo
P. $11-23$ 
9. SCHWARZ. “Um Seminário de Marx", p.95. ângulo de que se falava, para enfim nos equiparar aos países que nos servem de modelo. A nova intuição a que chega o grupo tem em conta que, nos países criados pela descolonização, vivemos em um espaço "diverso mas não alheio", um espaço em que as categorias que sustentam a ideologia plasmada nos países centrais não se aplicam com propriedade e nem podem deixar de ser aplicadas. Elas, aqui, giram em falso, ainda que sejam obrigatórias. O espaço é diverso porque a colonização obviamente não criava sociedades iguais às da metrópole, e nem a divisão posterior do trabalho internacional constrói igualdades. Mas trata-se de um espaço da mesma ordem, porque também ele é comandado pela dinâmica abrangente do capital. Ao invés de pensar o Brasi como o país do futuro, que um dia seria alcançado, o grupo nos ensinou a pensar a marcha do país como parte do desenvolvimento desigual e combinado, como formulou Trotsky, do capitalismo mundial.

Esse ponto de vista que se move entre o nacional e o internacional rege também a relação de Roberto Schwarz com a tradição do pensamento marxista em que se formou. Vejase como exemplo o que ele nos diz da inspiração lukacsiana de seu próprio trabalho. Ele assinala que os esquemas do romance europeu postos em circulação por Lukács não podem ser aplicados ao romance brasileiro. Isso por que este construiu um "modelo para a história europeia das ideias e do romance que depende da evolução histórica geral do feudalismo para o capitalismo e para o socialismo"10. Este esquema, embora embase as formas importadas aqui dos países europeus, não explica o desenvolvimento específico da arte no Brasil, uma nação que já começou como empreendimento do capitalismo mercantil. É também por isso que Schwarz diz que Lukács é básico em seu trabalho mas "como termo diferencial." Isso não impede que ele reconheça o que deve ao crítico húngaro:

Ele tem uma concepção muito forte e exigente do que constitui uma obra literária. As configurações, a busca inventiva da forma apropriada para o conteúdo, são consideradas ao mesmo tempo tarefa difícil e grande realização. E se o crítico for capaz de interpretar a forma artística e literária dando-lhe o seu conceito, ele vai dizer coisas relevantes. Assim Lukács atribui ao crítico uma missão importante da qual gosto muito. ${ }^{11}$

No caso de Roberto Schwarz, essa missão vai ser cumprida em todos os termos que a tradição dialética demanda Para Perry Anderson ele é o mais "acurado crítico dialético do mundo todo, desde Adorno”. ${ }^{12}$ Para Franco Moretti , em uma avaliação de 2006, sua obra tem a capacidade de demonstrar um dos elementos centrais para esta tradição, a concepção, segundo temos insistido aqui, de que a forma literária se configura como uma abstração das relações sociais
10. CORREDOR. “Entrevista com Roberto Schwarz", p. 28

EM TESE

BELO HORIZONTE

v. 21

N. 1

JAN.-ABR. 2015

CEVASCO. Roberto Schwarz: Um crítico dialético na periferia do capitalismo

P. $11-23$

11. CORREDOR. "Entrevista com Roberto Schwarz", p. 35

12. ANDERSON. “Lula's Brazil”. 
13. MORETI. "The End of the Beginning", p. 85. efetivamente existentes. Esse tipo de análise permite verificar que a forma artística é uma síntese que abre a possibilidade de uma compreensão intuitiva do todo social, dando-nos assim os elementos necessários para julgá-lo. Ainda segundo Moretti, uma combinatória similar de conteúdo de verdade, estilização e crítica aparece nas análises de Benjamin da obra de Baudelaire, de Dolf Oehler da de Heine e Flaubert, de Adorno sobre Schonberg, e de de T.J. Clark sobre Manet. ${ }^{13}$

O que têm em comum análises tão diversas? Em todas elas chega-se a um novo tipo de conhecimento sobre o todo social em que intervém a criação artística. Na linha de Walter Benjamin, ele afere como o desenvolvimento das forças produtivas incide sobre os modos do fazer artístico, em um movimento constante entre análise formal, a construção de tendências sociais e o que esse amálgama tem a nos dizer sobre o mundo contemporâneo. Um dos diferenciais de Roberto Schwarz é que ele faz essa análise do ponto de vista da periferia, mostrando como o estudo do que ocorre aqui pode iluminar o que se dá naquele espaço diverso do nosso, mas do qual somos parte integrante e reveladora. Para substanciar este ponto, quero finalizar apresentando um resumo de uma análise recente que Schwarz publicou sobre obra de Caetano Veloso. ${ }^{14}$

O ensaio já avisa no título a que vem: "Verdade Tropical: Um percurso de nosso tempo”. Ou seja, a questão é aferir um movimento típico de nosso momento histórico através da leitura da autobiografia de Caetano publicado em 1997. O Tropicalismo e o próprio Caetano já haviam sido um dos temas de um ensaio fundamental de Schwarz, publicado em 1970, “Cultura e Política 1964-1969”. Aí ele analisa um fato paradoxal da história recente do Brasil, a permanência de uma hegemonia cultural da esquerda mesmo após o golpe de 1964. Este é descrito como um momento de ruptura de um projeto incipiente de país: nos anos imediatamente anteriores ao golpe, armava-se um imaginário original em nosso país, que procurava pensar o Brasil por inteiro e do ângulo da necessidade da integração de todas as classes. Tratava-se de um projeto de mudança radical, que embora derrotado, constituiu um parâmetro para medir o significado real de progresso social, com o metro da igualdade e não com o de sempre, o do privilégio. Na avaliação do ensaio "Cultura e Política, 1964-1969":

Sob o signo da radicalização política, que beirou a pré-revolução, o programa tinha horizonte transformador. Em especial as artes públicas - cinema, teatro e canção - queriam romper com a herança colonial de segregações sociais e culturais, de classe e raça, que o país vinha arrastando e reciclando através dos tempos, e queriam, no mesmo passo, saltar para a linha de frente da arte moderna, fundindo revolução social e estética. Tratava-se por um lado de reconhecer a parte relegada e não-burguesa da nação, dando-lhe direito de cidade, e, por outro, de superar as alienações corres-
14. Retomo a partir daqui as ideias á apresentadas em CEVASCO. "Modernização à Brasileira."
EM TESE
BELO HORIZONTE
v. 21
N. 1
JAN-ABR. 2015
CEVASCO. Roberto Schwarz: Um crítico dialético na periferia do capitalismo
P. 11-23 
15. SCHWARZ. “Cultura e Política, 1964-1969", p. 55. pondentes a esta exclusão, que empobreciam a vida mental também dos incluídos. Graças ao espírito dialético, que estava em alta, os vexames de nossa malformação social - as feições de ex-colônia, o subdesenvolvimento - mudavam de estatuto. Em vez de varridos para baixo do tapete, eles passavam a ser identificados como interpelações históricas, em que estavam em jogo não só o atraso nacional como o rumo burguês e a desigualdade do mundo. ${ }^{15}$

Caetano Veloso e o Tropicalismo se formaram nessa atmosfera cultural, e lograram oferecer uma imagem reveladora do país. Schwarz lembra que o princípio formal centra dos procedimentos artísticos do Tropicalismo era a junção do arcaico e do moderno. Para ilustrar isso, vale lembrar a capa do disco "Panis Et Circensis" de 1968, juntando alguns dos artistas do movimento, Gilberto Gil com uma roupa ultra moderna para a época, um cruze de túnica e vestido com motivos que remetem à estética hippie então na crista da onda, carregando uma foto de formatura super tradicional e sentado ao lado do maestro Rogério Duprat, que segurava um penico como se fosse uma xícara de chá. Os arranjos musicais misturavam guitarras ultramodernas com batidas mais tradicionais da música brasileira, somado a um repertório que incluía músicas novíssimas como Bat Macumba de Gilberto Gil e Coração Materno (1937), que havia sido sucesso na voz do cantor brega Vicente Celestino. Esse procedimento figura, como destaca Schwarz, uma característica marcante do país, a coexistência fora do tempo do arcaico e do moderno.

Mas já nos efervescentes anos 1960, o crítico aponta uma limitação reveladora nessa figuração do país por Caetano e pelos Tropicalistas: essa junção de diferentes tempos e tipos de desenvolvimento se apresenta aí como algo "inelutável” e impossível de ser mudado: o movimento

registra, do ponto de vista da vanguarda e da moda internacionais, com seus pressupostos econômicos, como coisa aberrante, o atraso do país. [... o] estágio internacional é o parâmetro aceito da infelicidade nacional: nós, os atualizados, os articulados com o circuito do capital, falhada a tentativa de modernização social feita de cima, reconhecemos que o absurdo é alma do país e a nossa. ${ }^{16}$

A leitura de Roberto Schwarz da biografia de Caetano, publicada em 2012, específica os rumos que se anunciam nos primeiros anos do Tropicalismo. Nosso crítico faz uma leitura cerrada da biografia, reconhecendo seu interesse e relevância para debater o fundamental, ou seja, onde estamos e que horas são. Em retrospecto, essa leitura da biografia parece quase uma imposição do seu projeto intelectual: trata-se, como vimos, de explicitar, através da crítica cultural, a matéria brasileira, ou seja, a constelação formada pelo complexo peculiar de relações e posições que constituem nossa vida
16. SCHWARZ. “Cultura e Política 1964-1969", p. 90-91. 
local vista, como mencionamos nos achados do Seminário do Capital, do ângulo de sua inter-relação com o capitalismo internacional. A obra de Caetano é uma narrativa dos momentos decisivos da cultura brasileira contemporânea. O marco divisório é o golpe de 1964 que vem estancar, de forma abrupta, um outro projeto de país, um mais consoante com os ventos de mudança que sopram em muitos lados nos anos 1960, ventos estes que foram todos amainados pela vitória, não só em nosso país, das forças da reação. Este é um dos sentidos em que o golpe pode ser descrito como um momento fundamental não só da nossa vida política como também da Guerra Fria, momento que indica a derrota das forças de oposição à dominação irrestrita do capital, enfeixada na vitória, que se tornaria completa em 1989, do modo de vida defendido pelos Estados Unidos.

A narrativa de Caetano enfoca como ele viveu esse capítulo importante da história mundial. Sua figura de artista a um só tempo popular e de vanguarda enfeixa e esclarece o movimento. Ele nos conta, lembra Schwarz, sua infância e adolescência passadas em Santo Amaro, e como a maioria dos jovens de então, ele encarna um espírito rebelde e "de esquerda". Caetano descreve como era viver esse momento:

Falávamos de literatura, cinema, música popular; falávamos de Salvador, da vida na província, da vida das pessoas que conhecíamos; falávamos de política. Alvinho [um amigo] tinha rompantes heroicos: acho que foi ele quem me decidiu a colaborar com a campanha de alfabetização pelo método Paulo Freire, (mais tarde, depois do golpe, ele me levou a alguns encontros secretos para a formação de um "grupo dos onze", uma ideia de Leonel Brizola para organizar a resistência.) Embora política não fosse nosso forte nessa época - 63 - com os estudantes (organizados na UNE) apoiando o presidente João Goulart, ou pressionando-o para ir mais à esquerda; com $\mathrm{Mi}$ guel Arraes fazendo um governo admirável em Pernambuco em estreita união com as camadas populares, com os CPCs da UNE produzindo peças e canções panfletárias mas muito vitais; éramos levados a falar frequentemente de política: o país parecia à beira de realizar reformas que transformariam a sua face profundamente injusta - e de alçar-se acima do imperialismo americano. Vimos depois que não estava sequer aproximando-se disso. E hoje nos dão bons motivos para pensar que talvez nada disso fosse propriamente desejável. Mas a ilusão foi vivida com intensidade - e essa intensidade apressou a reação que resultou no golpe. ${ }^{17}$

Estão elencados aí muitos dos elementos da hegemonia cultural da esquerda a que se refere o ensaio "Cultura e Política, 1964-1969”. Os Centros Populares de Cultura da União Nacional dos Estudantes revigorando as artes brasileiras com sua preocupação de levar a arte onde o povo está; a música popular tentando dar conta da história do momento, o método Paulo Freire, oferecendo, no mesmo gesto, a
17. VELOSO. Verdade tropical, p. $63-4$. 
leitura do alfabeto e a leitura do mundo àqueles a quem tudo fora sempre negado no país da desigualdade; a resistência política; a intensidade desses anos de promessas. É justamente nessa hora chave da vida do Brasil que Caetano dá a virada que é o interesse de Schwarz demonstrar. Trata-se de ver como se modifica uma trajetória de esquerda diante do impasse de escolhas que representa o golpe. Uma vez derrotado o projeto de um país democrático, que faz uma pessoa de esquerda?

Nosso crítico pinça uma cena-chave na narrativa de Caetano que configura o rumo escolhido diante das opções que a História oferecia. $\mathrm{O}$ assunto é justamente uma reação ao filme de Glauber Rocha, “Terra em Transe”, que formaliza questões fundamentais para a esquerda dos anos 1960. Na cena, vemos a reação de um intelectual, Paulo Martins, que se alia à causa popular e se engaja em uma campanha política em um país fictício que é claramente o Brasil. No meio da campanha, ele se irrita com um dirigente sindical que o chama de doutor. Ele tapa a boca do líder e se dirige ao público a pergunta "Estão vendo quem é o povo? Um analfabeto, um imbecil, um despolitizado". Como ensina Schwarz:

Meio sádico, meio auto-flagelador, o episódio sublinha entre outras coisas a dubiedade do intelectual que se engaja na causa popular ao mesmo tempo em que mantém as avaliações con- servadoras - raramente explicitadas como aqui - a respeito do povo. Ditada pela evidência de que não haveria revolução, a desqualificação dos trabalhadores é um desabafo histórico, que no passo seguinte leva à aventura da luta armada sem apoio social. Do ponto de vista da esquerda, a cena - uma invenção artística de primeira força - era um compêndio de sacrilégios, fazendo uma espécie de chacota dolorosa das certezas ideológicas do período. Os trabalhadores estavam longe de ser revolucionários, a sua relação com os dirigentes pautava-se pelo paternalismo, os políticos populistas se acertavam com o campo adversário, a distância entre as teses marxistas e a realidade social era desanimadora, e os intelectuais confundiam as razões da revolução política e as urgências da realização pessoal. Nem por isso se atenuavam as feições grotescas das camadas dirigentes e da dominação de classe, que continuavam em pé, esplendidamente acentuadas. A revolução não se tornara supérflua, muito pelo contrário: encontrava-se num beco histórico e não dera o necessário passo à frente. A nota geral era de desespero. ${ }^{18}$

Ora a leitura de Caetano da mesma cena revela com precisão um dos rumos fundamentais que certas correntes da esquerda vão tomar após o golpe:

Vivi essa cena - e as cenas de reação indignada que ela suscitou em rodas de bar - como o núcleo de um grande acontecimento cujo nome breve que hoje lhe posso dar não me ocorrera com
18. SCHWARZ. Martinha versus Lucrécia, p.76-7. 
19. VELOSO. Verdade tropical, p. 104-5.

20. VELOSO. Verdade tropical, p 116 tanta facilidade então (e por isso eu buscava mil maneiras de dizê-lo para mim mesmo e para os outros): a morte do populismo. (...) era a própria fé nas forças populares - e o próprio respeito que os melhores sentiam pelos homens do povo - o que aqui era descartado como arma política ou valor ético em si. Essa hecatombe eu estava preparado para enfrentá-la. E excitado para examinar-lhe os fenômenos íntimos e antever-lhe as consequências. Nada do que veio a se chamar de 'tropicalismo' teria tido lugar sem esse momento traumático. 19 "Portanto, quando o poeta de Terra em transe decretou a falência da crença nas energias libertadoras do 'povo', eu, na platéia, vi, não o fim das possibilidades, mas o anúncio de novas tarefas para $\operatorname{mim} .{ }^{20}$

Ressalte-se a leitura correta que Caetano faz da hecatombe que foi, para a esquerda, essa noção da perda da fé no povo que seria tarefa histórica integrar para se formar um país menos iníquo. O povo não mais como objeto de respeito, ou como arma política ou como portador da consciência que é preciso levar a todos para que haja a abolição das classes. Estava figurado nessa imagem artística potente o desarme de todo um esquema que havia sustentado a prática política das diferentes correntes da esquerda. Quanto às novas tarefas, sabemos quais foram: substituir o impulso revolucionário pelo rebelde, substituir a política de classe pela das identidades. A escrita de Caetano dá notícia dos rumos que

EM TESE
BELO HORIZONTE

v. 21

N. 1

JAN.-ABR. 2015 certa esquerda vai tomar, e, como sempre, não só no Brasil. Caetano se alegra por que vê aí o fim de uma política anticapitalista. Agora fica justificado, sempre da sua ótica, juntar-se ao mais "moderno", o capitalismo internacional, que mantém o mais arcaico, a exploração do povo, que agora, além de tudo, tem que levar a pecha de ter perdido o respeito dos ditos "melhores". Estes, agora, podem travar batalhas mais palatáveis ao sistema dominante. Este é um dos sentidos em que a autobiografia do grande artista popular descreve uma "trajetória de nosso tempo", um tempo que recusa o desejo de mudança radical.

A leitura de Roberto Schwarz exemplifica, mais uma vez, o poder de revelação da crítica dialética.

\section{REFERÊNCIAS}

ANDERSON, Perry. "Lula's Brazil". London Review of Books, v. 33, .n.7, p. 3-12, mar. 2011

ARANTES, Paulo Eduardo. Sentimento da dialética na

experiência intelectual brasileira. São Paulo: Paz e Terra, 1992.

CANDICO, Antonio. "Feitos da burguesia", In: Teresina Etc. São Paulo: Paz e Terra, 1992, p.87-96.

CEVASCO, Maria Elisa. "Modernização à Brasileira". Revista do Instituto de Estudos Brasileiros, Brasil, n. 59, p. 191-212, dec. 2014, disponível em: <http://www.revistas.usp.br/rieb/article/ view/89042>. 
CORREDOR, Eva L.. "Entrevista com Roberto

Schwarz". Literatura e Sociedade, São Paulo, n. 6, p. 14-37, dec.

2002.

HADDAD, Fernando (org). Desorganizando o consenso: nove

entrevistas com intelectuais à esquerda. Petropolis: Vozes, 1998

MORETI, Franco. "The End of the Beginning", In: New Left

Review, v.41 Sept/Oct, 2006.

Roberto Schwarz. "Adequação Nacional e Originalidade Crítica",

In: Sequências Brasileiras. São Paulo: Companhia das Letras, 1999

Roberto Schwarz. "Cultura e Política, 1964-1969", In: O Pai de Família e outros estudos. [1978] São Paulo: Companhia das

Letras, 2008, p.70-111.

Roberto Schwarz. Martinha versus Lucrécia e outros ensaios. São Paulo: Companhia das Letras, 2012.

Roberto Schwarz. "Sobre Adorno", In: Martinha versus Lucrécia São Paulo: Companhia das Letras, 2012, pp. 44-51.

Roberto Schwarz. Um mestre na periferia do capitalismo

Machado de Assis. São Paulo: Duas Cidades, 1990.

Roberto Schwarz. "Um Seminário de Marx", In: Sequências Brasileiras. São Paulo: Companhia das Letras, 1999.

VELOSO, Caetano. Verdade tropical. São Paulo: Companhia das Letras, 1997. 